\title{
The Artistical Conceptualisation of Jewellery Works for Circus Artists
}

\section{Sidra Qazi ${ }^{1}$ " , Hafiz Hussnain Barkat Qazi ${ }^{2}$, Shaukat Mahmood ${ }^{1}$, Sumera Jawad ${ }^{1}$, Muntaha Qazi ${ }^{3}$, Muhammad Akram Qazi ${ }^{4}$}

${ }^{1}$ University College of Arts and Design, University of the Punjab, Allama Iqbal Campus, Lahore, Pakistan

${ }^{2}$ Pakistan Institute of Fashion and Design, Lahore, Punjab, Pakistan

${ }^{3}$ Institute of Education and Research, University of the Punjab, Lahore, Pakistan

${ }^{4}$ Soil Fertility Research Institute Punjab, Lahore, Pakistan

Email address:

sidraqazisidraqazi@gmail.com(S. Qazi),sidraqazi55@yahoo.com(S. Qazi)

${ }^{*}$ Corresponding author

\section{To cite this article:}

Sidra Qazi, Hafiz Hussnain Barkat Qazi, Shaukat Mahmood, Sumera Jawad, Muntaha Qazi, Muhammad Akram Qazi. The Artistical Conceptualisation of Jewellery Works for Circus Artists. American Journal of Art and Design. Vol. 5, No. 2, 2020, pp. 45-49.

doi: 10.11648/j.ajad.20200502.14

Received: July 1, 2020; Accepted: July 14, 2020; Published: July 30, 2020

\begin{abstract}
The idea behind the research study lies mainly in the traveling art of the artist, as well as in her friendliness and affection for the poor young performers of the circus, as well as in the refreshing of old recreation shows. The resilient nation of Pakistan has long suffered the turmoil of terrorist attacks. Such heinous acts against civilians and security forces have created, albeit short-lived, a sense of demoralization in the society. The research was conducted as a qualitative analysis and covered the back story of homelessness and at-risk Circus youth / artists, life style (container / cottage), difficulties, learning, travel, and management, etc. It is a unique attempt in Pakistan's Art Studio to design and manufacture contemporary jewelry pieces (brooches) reflecting the circumstances of the Circus youth / workers / artists' lifestyle, physical and emotional integrity was a rich source of inspiration that motivated me during my replication and analysis process. For circus artists, the carnival continues to travel; it keeps moving from one city to another to perform and entertain people. Hence highlighting their societal challenges and being closely associated to political, cultural and artistic realities. The art pieces of the project help to illustrate and understand the lives of circus performers, deprived of the freedom of the conditions under which they work, and the fun fashion they adopt in return.
\end{abstract}

Keywords: Circus Performers, Contemporary Fashion, Brooches, Life Style, Jewellery, Creative Realities

\section{Introduction}

The idea behind the research study lies fundamentally in the traveling art of the artist, as well as in her friendliness and affection for the poor young performers of the circus, as well as refreshing an old recreational show in Pakistan called "Lucky Irani Circus," which is a registered circus in the region. Pakistan's resilient country has long undergone the chaos of terrorist attacks [1,2]. Together these heinous actions against civilians and security forces created a sense of demoralization in our society, albeit a short-lived one [3]. In the present review, focus will be put on the lives of circus artists behind the curtain [4] and an approach that can be mixed and reflected in jewelry art. The research work has been identified with the intention of analyzing its historical context and conceptual framework in order to address the implications subsequently while keeping in mind the research goals at the same time. Depressed and perplexed by an continuing outbreak of terrorist violence, the people of Pakistan want some leisure $[5,6]$. And, what better way to freshen their minds by watching a fine kind of classic entertainment $[7,8,9,10,11,12]$. Such events encourage young people to develop and guide their own stories in fanciful and imaginative ways. We do give them the opportunity to engage with the viewers through the production of special, exciting shows. Circus is one of the 
best known and versatile enterprises in Pakistan, known for its leisure activities [13]. Continuous travel is the requirement for circus artists; they have to switch from one town to another to perform and entertain people [4, 14]. Among their performers there are those who fled their homes an4d entered the carnival as the only choice in their adolescence $[15,16]$, while others are the individuals who joined the circus at will as a profession. Most of the artists join the ring at three or four years of age and spend all their lives on the wheel there. The work will cover all of the backstage tales and ordeals of homelessness, life at risk (container / cottage), circus performer / artist issues, teaching, education, travel and management, and so on. The researcher's main focus will be on designing and creating contemporary artistic (wearable and non-wearable) objects that reflect the lifestyles, physical and emotional integrity, and the circus performers / artists 'living conditions, thus illustrating the difficulties they face. The study's most significant aspect was the production of contemporary art pieces associated with the aesthetics and physical structure of the circus to reflect the revival of this much-loved local recreational show. The pieces of art help to explain and portray the lives of acrobats stripped of their freedom in the environments they work in, and the friendly fashion they follow in exchange. Both these elements will be represented in culture, and will also be closely related to today's world's physical, cultural and artistic conditions. This research study would therefore highlight the long-lost display of our society, highlight the lives of people working there and explain the three main elements: surprise, play and trick.

\section{Materials and Methods}

This was how the whole process made progress; from the research phase to the creation of works of art, exploratory research, and methods of data collection used in this research. The current work focused on non-experimental research based architecture. Different individuals, acrobats and employees were interviewed in order to decide their status and lifestyle on Circus's location. Much of the analysis concentrated on qualitative data, while a smaller part still deals with quantitative data; a mixed-method approach was therefore adopted. The research procedure began when the concept was being developed. The approach to qualitative research was used to collect data and to gather more and more information about the circus. In this regard, the source of inspiration was the multitudes of circus performers who were closely connected to each other and their connection to what they do, i.e., acrobatic shows and other performances. So, the primary focus of the instant analysis was an indigenous Pakistani circus (Lucky Irani Circus) to get fresh and innovative ideas for the design process. A secondary research aimed at browsing the internet was also part of the process, to gather knowledge from very informative articles and blogs. Similarly, interviews were conducted as a principal source with the individuals connected with the circus. The development of the product was carried out during the design and extraction process in the form of sketches as well as physical objects. Several designs and materials were subsequently explored to implement various ideas complementing the subject. Two investigative resources, i.e. Questionnaires and interviews were used to collect data, both qualitatively and quantitatively. A number of prestigious exhibitions have been visited such as "Daachi Arts and Crafts," as well as personal visits to art galleries in Lahore, Pakistan such as "Ejaz Gallery," "Alhamra Art Gallery," "Shakir Ali Museum," Unicorn Art Gallery and other important centers to find out if pieces related to cultural activities and displays have been acknowledged. Artist herself witnessed Lucky Irani Circus and was visiting at a festival in the village of Bodianwala, Tandlianwala, Faisalabad along with her father and aunt. Here are some Festival picture (Figures 1 - 9).

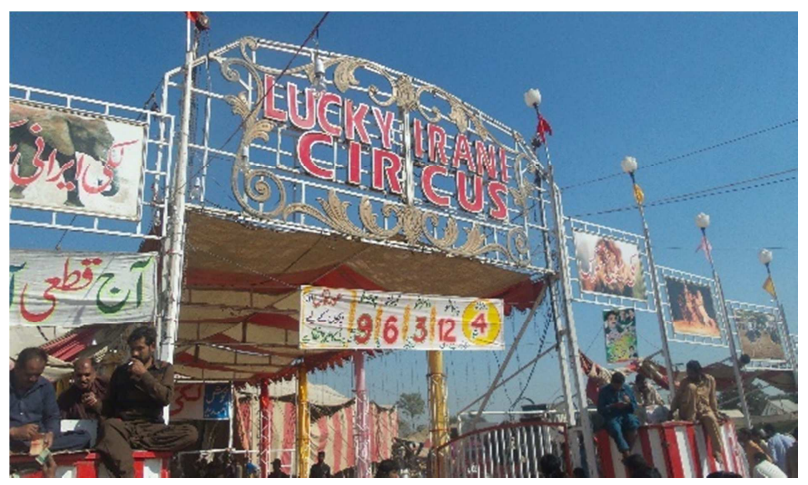

Figure 1. Photography of the Lucky Irani Circus on the eve of the village festival.

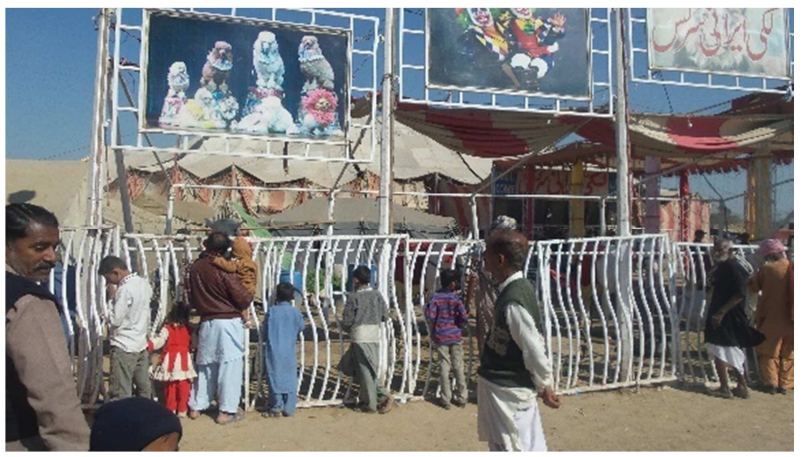

Figure 2. Photography of the Lucky Irani Circus on the eve of the village festival.

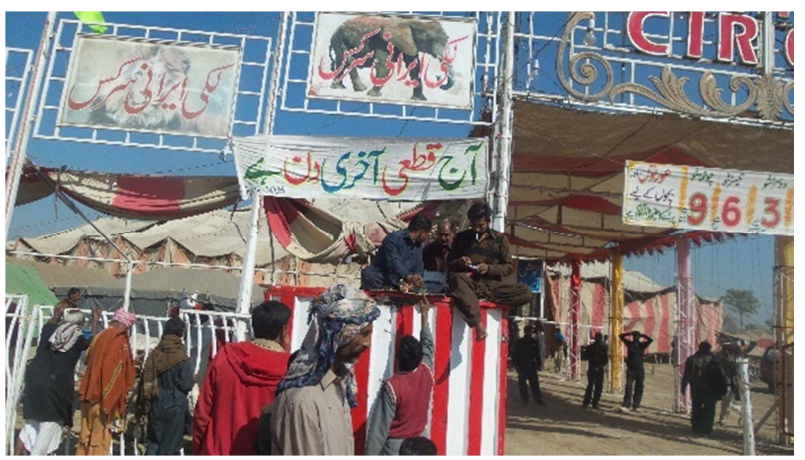

Figure 3. Lucky Irani Circus advertising banners displayed on the eve of the village festival. 


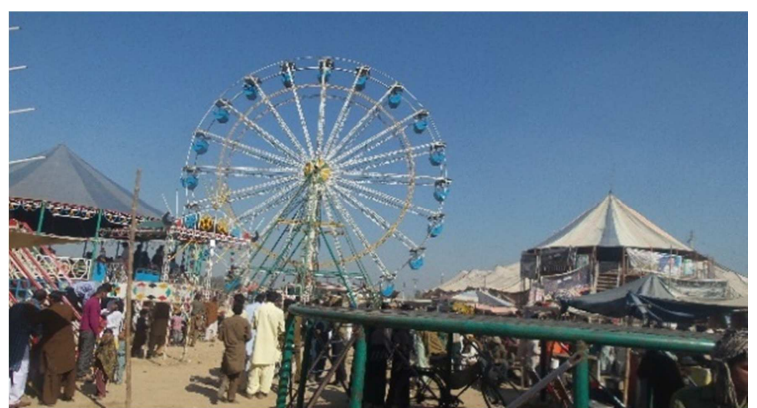

Figure 4. A festival glimpse.

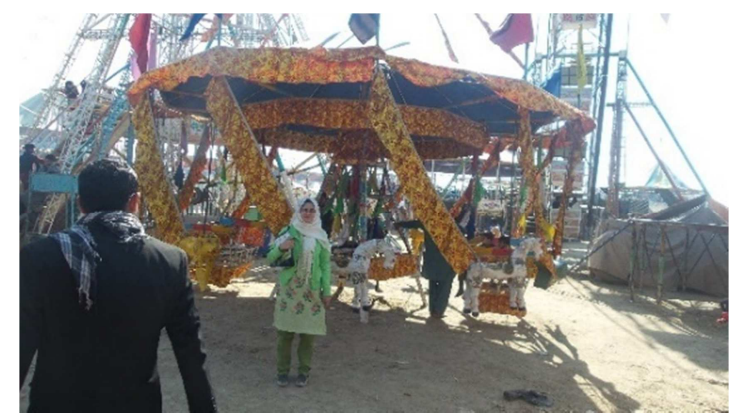

Figure 5. Sidra Qazi, in a village circus festival.

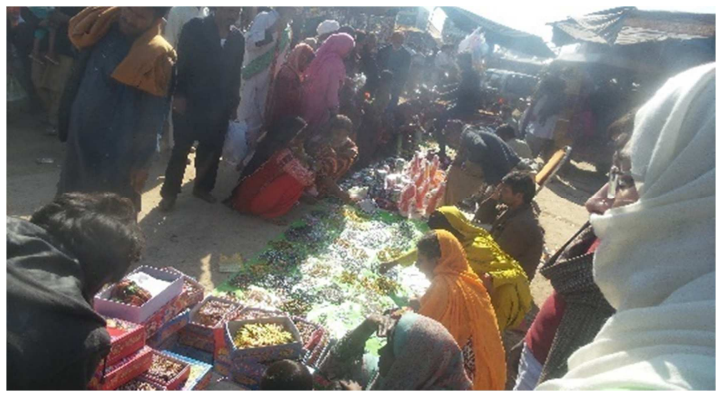

Figure 6. Village women are busy purchasing festival jewellery.

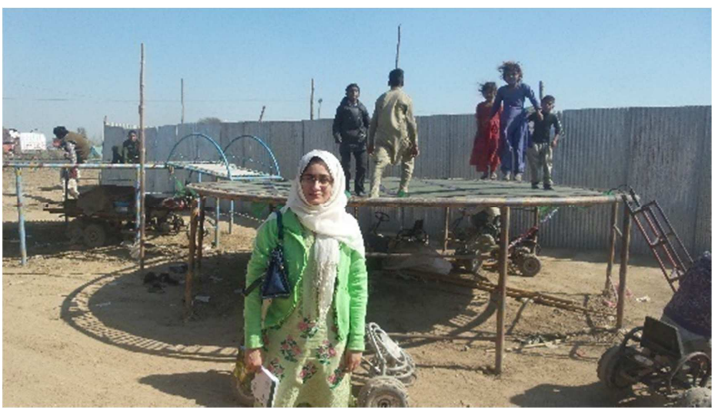

Figure 7. Village kids love leisurely jumping.

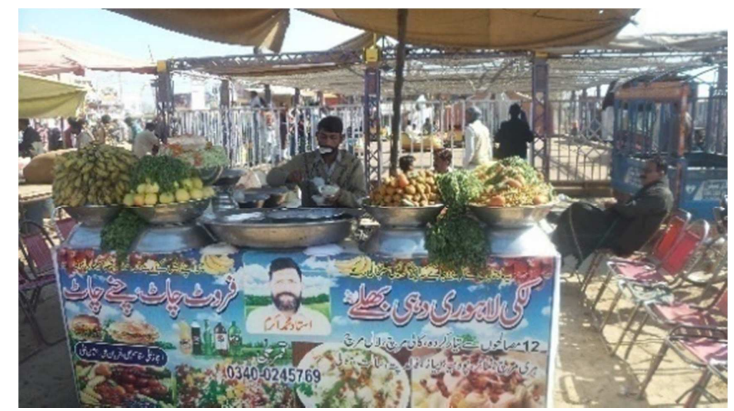

Figure 8. Local fast-food spot for village festival attendees.

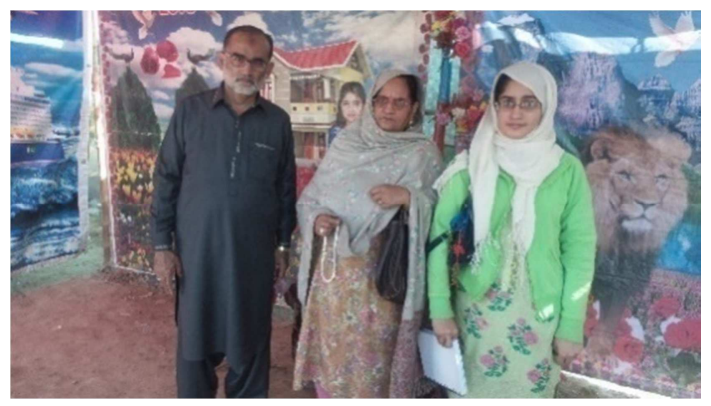

Figure 9. Artist, her dad and aunt experience the festival.

Furthermore, the purchasing patterns and consumer preferences were closely examined with the goal of understanding what kind of people are coming and demanding the local tinge in the art pieces rather than purchasing western style and creating posts. After removing elements, which was not only interesting but also remarkable, the artist started to combine them into an art piece. For the development of a single article the artist drew several sketches.

Artistic design masterpieces

The designer preserves and promotes cultural heritage and local practices, performs historical, creative and cultural studies that represent the customer's interest. Artistic conception that refers to the feeling and situation reflected in the works of literature or the natural environment. Jewellery also holds the most precious history and memories of human life and is the messenger of personality, time and culture. By modifying the jewellery, and also preserving the artistic features of an age. Particularly, further humanistic care and moral support are expected of modern people. Contemporary gemstones are no longer merely decorations. But always to seek a kind of happiness and nourishment on the personal level. Designers brought their fostered emotions into the jewellery design framework by using creative expression invention to convey the deep connotation of the work. It creates a connection as a mechanism between the jewellery manufacturer, the client, and the spectator $[17,18]$. The goal of this study is to outline and evaluate the possible social, cultural and technical facets of circus artists, both positive and negative, of hand-crafted pieces of jewellery crafted by a craftsman in Lahore, Punjab, Pakistan.

Artile-1

Creative artistic jewellery development is accomplished with certain engineering skills, and personal imaginations and realistic thought are put in place. On this development the author's intellectual framework, thoughtful thinking, distinctive personality traits and character feeling are clearly apparent. In article-1, the designer reveals the intense feeling of love and affection for circus performers. Various forms, shapes, styles and acts of the circus have been included in this work (Sketch and figure 10). The studied piece of jewellery is called "Brooch" has been used since ancient times with a proliferating arrangement that creates a dazzling decorative effect similar to a starry sky. This conceptual design shows the theme of the Lucky Irani Circus, the design elements and the various performances. This has been developed at various 
stages, e.g. master features, design development, elements development and article production. This brooch shows the different acts of the Circus, including the crown act, the swinging act and the magic show. Various forms, shapes, styles and acts of the circus have been included in this piece. Techniques included soldering, enameling, custom stone setting, wire twisting and fret work used in the manufacturing process. It displays the elephant trunk, the artist's dress and shoes, the circus baseball, the bird's beak, a different stylized styles from the circus. Copper was used as base metals in this art piece. Twisted wire of different gauges was used for the boundary in this piece. Green and blue custom enamel (depending on the shape) were used. Green color reveals the baseball circus, a textured sheet was used for the bird's body and the elephant's trunk. Enameling was used for the shiny effect that complements the brightness and fame of the circus. Its assessment highlights the value of the product itself in terms of materials and manufacturing and generates shared value for the circus community and promotes artisan craft activities and related cultural and professional activities. The present study further shows how the positive impacts and the intrinsic worth of the artisanal piece of jewellery as seen in the brooch provide mutual gain to people and circus performers as they spent their life in golden time for fun and entertainment. The key contribution is the recognition of the ability of the artists by emphasizing its positive social effects on the local community.
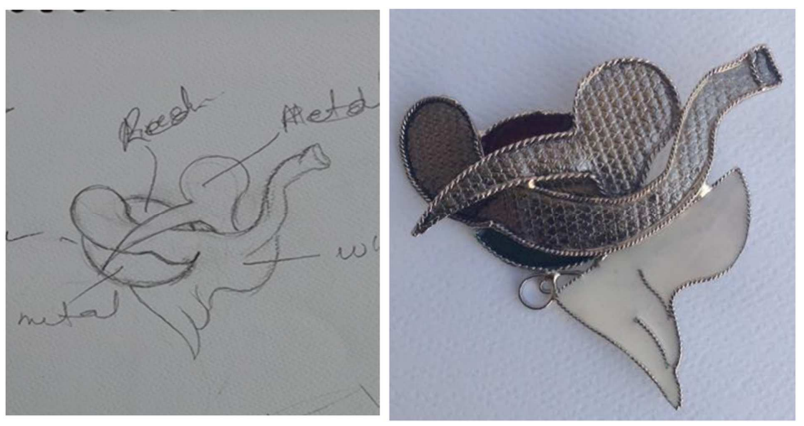

Figure 10. Sketch and piece of jewellery designed by Sidra Qazi.

\section{Artile-2}

In this article, the conceptual approach is based on the theme, the arrangement of the elements and the various performances of the Circus. This design has been developed at various levels, such as master part, design-development, system development and article development. A piece of brooch depicts the bird from the circus act, the bird's beak with a pointed tip, the actor holding a ball with his feet in an act etc. The techniques like soldering, enameling, custom stone setting, wire twisting and fret work were used in the manufacturing process. Steel was used as the base metal. Twisted wire of different gauges was used for the boundary of this item. Two different textured sheets were used in the background. Green enamel (depending on the shape) was used. Steel base metal reveals the body of a bird. Enameling was used for a shiny effect that complements the brightness and prestige of the circus.

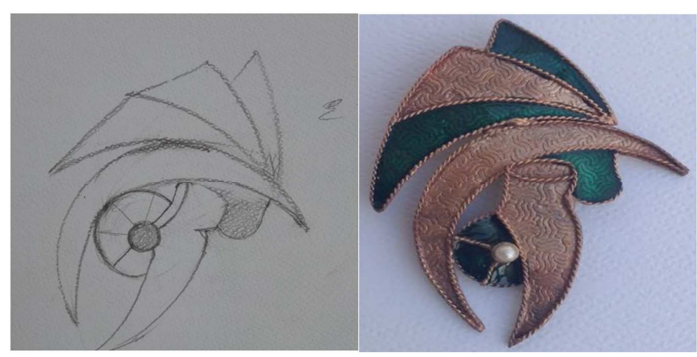

Figure 11. Brooch concept sketch and jewelry set, designed by Sidra Qazi.

\section{Article 3}

This work of art shows the essence of Circus. The circus featured various forms, sizes, types, and performances. Techniques used for manufacturing included soldering, enameling, custom stone setting, wire twisting, and fret work. In this item, twisted wire of varying gauges was used. This piece of art depicts the ring of the circus performer, the elephant playing a ball with teeth, the crown wearing a hat performing magic, etc. Copper was used as the reference metal in this work of jewellery. The green color exposes the circus performer's ring, and the blue color depicts crown wearing a hat. Twisted wire revealed elephant teeth. In the circular portion of the work of art, bright red and white enameling was used to denote a ball which elephant plays with teeth. Enameling has been used for the genius effect that complements the circus light and glory.
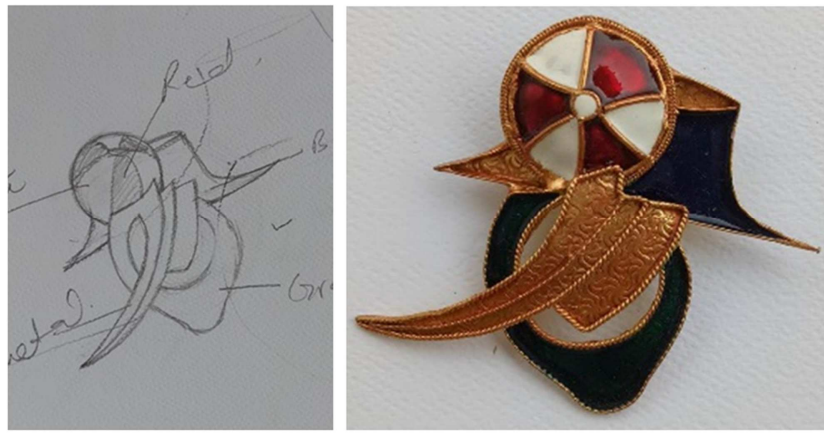

Figure 12. Brooch pattern and piece of jewelry designed by Sidra Qazi.

\section{Article 4}

This art work shows the joker face mask during the circus act, the crown leg, the joker wearing hat during the act, the joker hanging upside down, the circus bird beak and the chains and ropes the actors used during their performances. Techniques used in the manufacturing process included soldering, enameling, custom stone setting, wire twisting, and fret work. This work of art displays numerous circus activities. Various sizes, shapes, designs, and circus acts were used in this piece. Copper and brass were used as the base metals in this work of art. In this section twisted wire of varying gauges was used. Simple surface was included, too. Red, and red pattern enameling was used to designate the colors of the circus sheds. For certain areas of the art work deep red paint is used to describe the circus artists' costumes. The article's blue paint area reveals crown head. Stones were used for the glittering effect that complements the circus 'light and prestige. The 
bird's beak is depicted in green and red colors. Golden enameling area shows the crown face made of round wire.
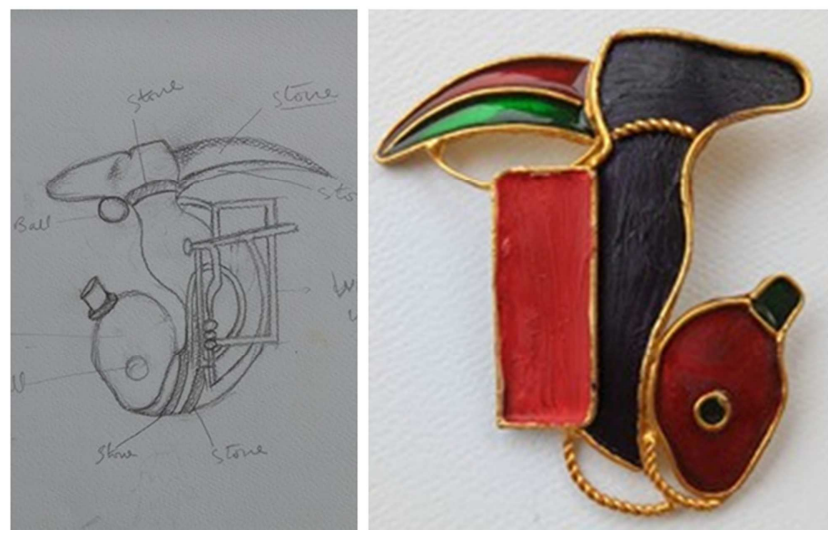

Figure 13. Brooch drawing and jewelry pattern by Sidra Qazi.

\section{Conclusion}

The current research study focused on the traveling art of artists, the behind - the-curtain life of circus performers, and the resulting approach was one that could be combined and portrayed in jewelry art. The research issue has been identified with the aim of reviewing its historical history and conceptual context in order to resolve the implications, as well as refreshing an old recreation show called the "Lucky Iranian Circus" in Pakistan. The art pieces of the project contribute to illustrating and understanding the circus performers 'lives. These are also the voices of circus performers, their perspectives and insights which the researcher would be able to understand in the future as a significant and useful tool for arts planners and experts. Artistic activity narrates the importance of artists 'contribution to circus art, to culture, and shows how interest in expressions through culture affects the individual. This also informs how the characteristic value of circus workmanship is to gain and maintain a social esteem. A comprehensive education system for circus performers should be structured to help and promote their own and societal development. Last but not least, the researcher believes that a National Youth Recreation Program, especially for those in rural areas, should be implemented with the intention of promoting recreational activities, particularly in the circus, with the aim of providing young people with a variety of value recreational opportunities to enhance their lives and advance their physical, mental and social well-being.

\section{References}

[1] Khan, A. U. (2005). The Terrorist Threat and the Policy Response in Pakistan, SIPRI Policy Paper no. 11 (Stockholm: Stockholm International Peace Research Institute, September 2005), pp. 31-32, 35-44, http://books.sipri.org/files/PP/SIPRIPP11.pdf.
[2] Kalim, S. \& Janjua, F. (2019) '\#Weare United, cybernationalism during times of a national crisis: The case of a terrorist attack on a school in Pakistan', Discourse and Communication, 13 (1), pp. 68-94.

[3] Tellis, A. J. (2008). Pakistan and the War on Terror: Conflicted Goals, Compromised Performance, Washington D. C.: Carnegie Endowment for International Peace.

[4] Alzaga, M. (2007). The travelling lives of circus artists: Home and Homelessnes in a Nomadic Life. Ethnologia Europaea Journal of European Ethnology, 37: (1-2), 51-57.

[5] Fayyaz, S. (2010). "Pakistan Response Towards Terrorism: A Case Study of Musharraf Regime." PhD diss., The University of Birmingham.

[6] Feyyaz, M. (2016). The discourse and study of terrorism in decolonised states: the case of Pakistan. Critical Studies on Terrorism, 9 (3): 455-477.

[7] Sadaf, S. (2018). Human dignity, the "war on terror" and post9/11Pakistani fiction. European Journal of English studies 22 (2): $115-127$.

[8] Spiegel, J. B., Breilh, M. C., Campaña, A., Marcuse, J., \& Yassi, A. (2015). Social circus and health equity: Exploring the national social circus program in Ecuador. Arts \& Health, 7 (1); 65-74.

[9] Spiegel, J. B. (2016). Social Circus: The Cultural Politics of Embodying "Social Transformation". TDR/The Drama Review, 60 (4); 50 - 67.

[10] Elena, L. K. (2018). Contemporary Circus Mobilities. Performance Matters, 4.1-2: 93-98.

[11] Sorzano, O. (2018a). Circus Between Centre and Periphery: The recognition of the form in 21st Century Britain and Colombia (PhD). City, University of London, London. 134.

[12] Sorzano, O. (2018b). Is Social Circus "The Other" of Professional Circus? Performance Matters, 4 (1-1): 116-133.

[13] Burton-Morgan, P. (2018). A New Era for Women in Circus. Exeunt Magazine. Retrieved from $\mathrm{http} / /$ exeuntmagazine.com/features/new-era-women-circus/

[14] Lipphardt, A. (2012). "Artists on the Move. Theoretical Perspectives. Empirical Implications." In a. RTISTS IN TRANSIT / How to Become an Artist in Residence, edited by Annette Hollywood and Andreas Schmid, 109-22. Berlin: Internationale Gesellschaft der Bildenden Kunste.

[15] Burtt, J., \& Lavers, K. (2017). Re-imagining the development of circus artists for the 128 twenty-first century. Theatre, Dance and Performance Training, 8 (2): 143-155.

[16] McCaffery, N. (2014). Social Circus and Applied Anthropology. Anthropology in Action, 21 (1); 30-35.

[17] Kopidou, D., A. Tsakanikas, et al. (2016). "Common trends and drivers of $\mathrm{CO}_{2}$ emissions and employment: a decomposition analysis in the industrial sector of selected European Union countries." Journal of Cleaner Production, 112, Part 5: 4159-4172. doi.org/10.1016/j.jclepro.2015.06.079.

[18] Xiaoyan, Z. \& Xu, Z. (2016). Research on the beauty of artistic conception in jewelry design. IOSR Journal of Engineering. 6 (3): 2278-8719. 